\title{
Extensive disseminated cysticercosis
}

\author{
Ming-Pin Lin, ${ }^{1}$ Yen-Li Chen, ${ }^{2}$ Wen-Sheng Tzeng ${ }^{1}$
}

${ }^{1}$ Department of Radiology, Chi-Mei Foundation Medical Center, Tainan, Taiwan ${ }^{2}$ Department of Medical Technology, Chen Shiu University, Kaohsiung, Taiwan, Taiwan

\section{Correspondence to} Dr Ming-Pin Lin, linmikea@yahoo.com.tw

\section{DESCRIPTION}

We present the case of a 74-year-old patient who, as an adult, enjoyed eating uncooked pork and beef. Recently, he had suffered from a sudden onset of gait disturbance, memory loss and disturbance of consciousness. He was brought to the emergency department for evaluation. On arrival, his vital signs were stable. The physical examination revealed mild weakness of the right extremities

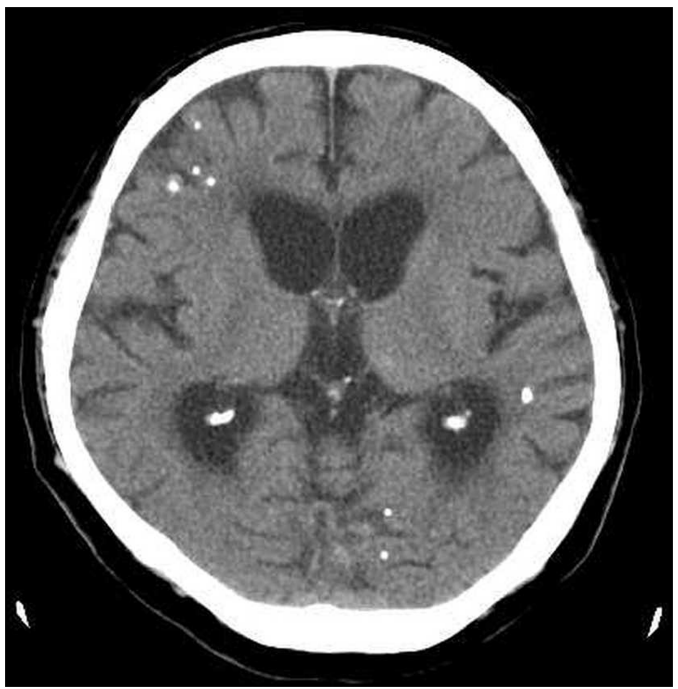

Figure 1 Brain CT revealing innumerable hyperdense 'dot' in the brain parenchyma.

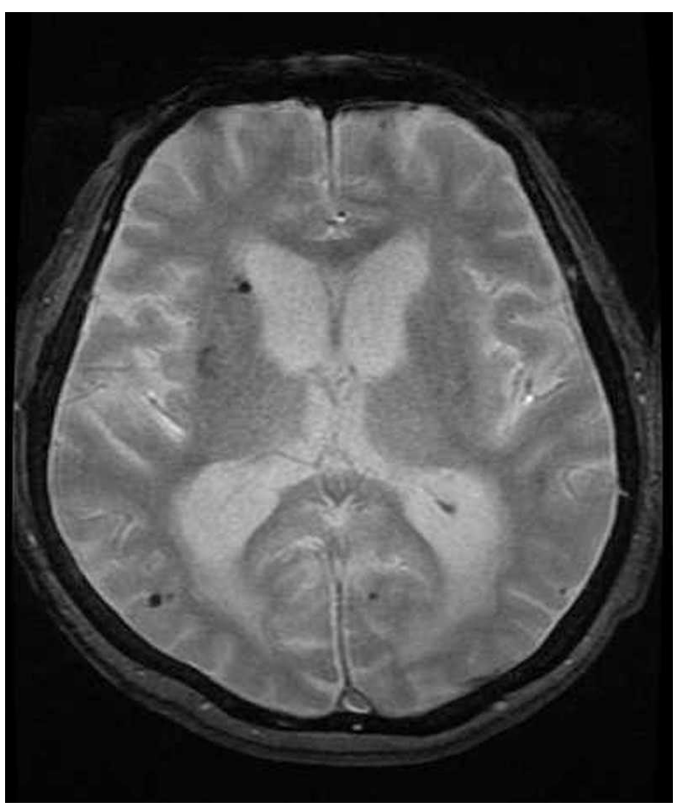

Figure 2 Brain MRI showing that the numerous hypointense cysts are in the brain parenchyma. (muscle strength grade 3/5), slurred speech, left facial palsy and general appearance of weakness. ELISA was positive, as were serum and cerebrospinal fluid (CSF) parasite antibody immunoglobulin $G$ for cysticercosis. We strongly suspected neurocysticercosis.

The brain CT scan (figure 1), brain MRI (figure 2), abdominal CT scan (figure 3) and plain X-rays (figures 4-9) had a characteristic 'starry sky'

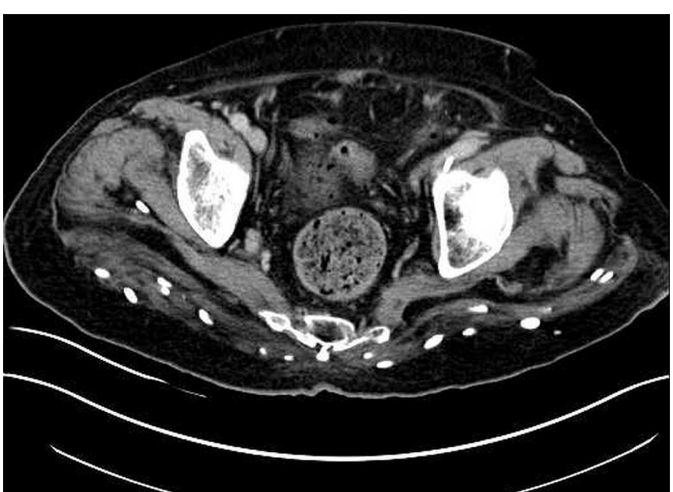

Figure 3 Abdominal CT revealing innumerable hyperdense 'dot' in the para lumbar spine and gluteal muscles.

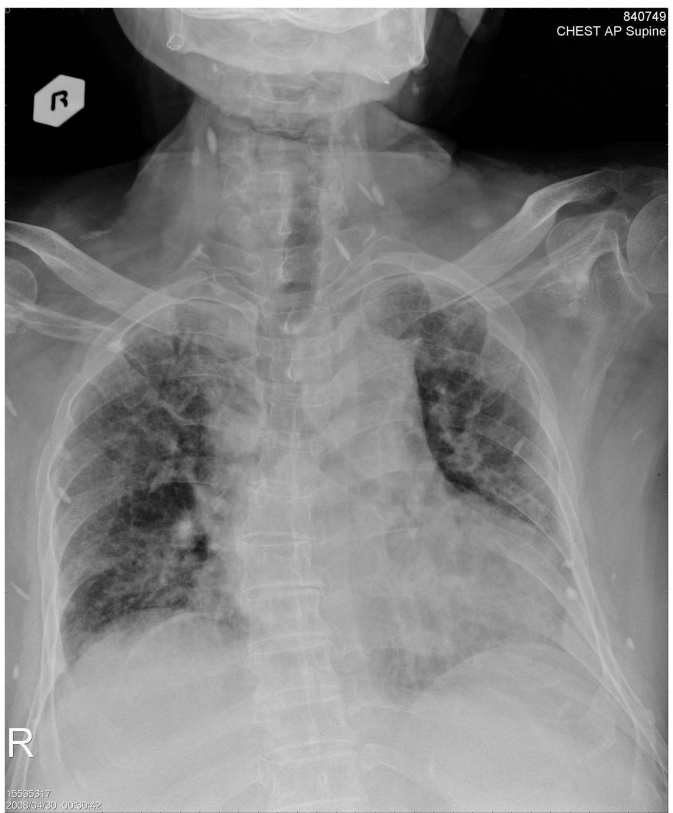

Figure 4 Chest film revealing numerous cysticerci on the neck and chest wall regions. 


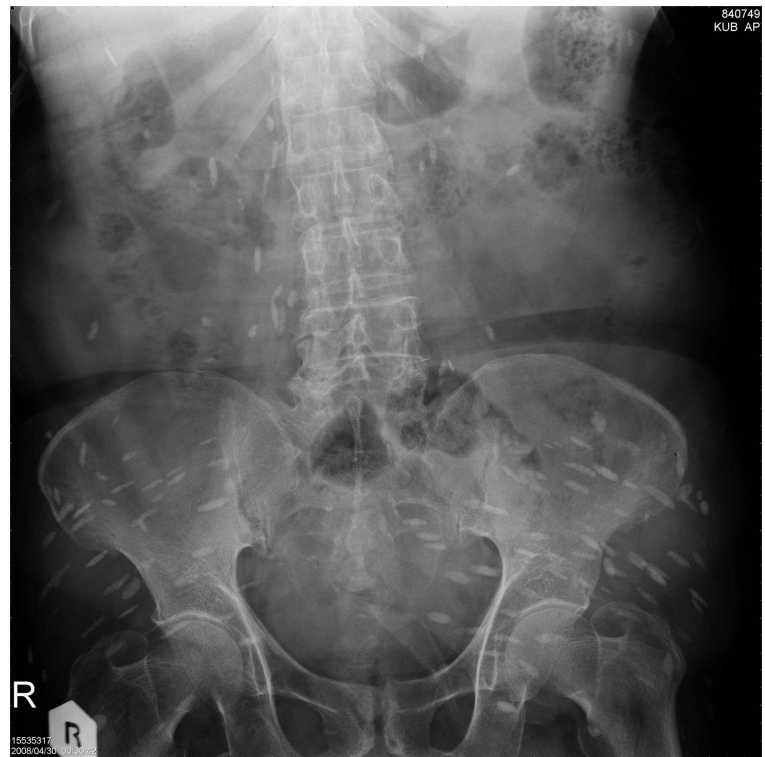

Figure 5 Kidneys, ureters, and bladder X-ray film revealing numerous cysticerci on the gluteal and iliopsoas muscle regions.

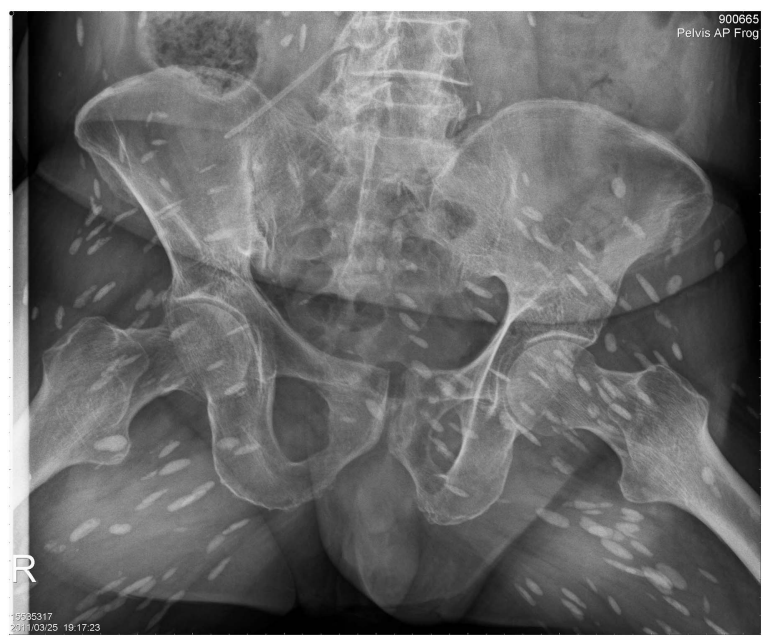

Figure 6 Pelvis film revealing numerous cysticerci on the gluteal and iliopsoas muscle regions.

appearance, revealing calcified foci in muscles. Treatment of neurocysticercosis lesion includes administration of albendazole and steroids, and surgical ventriculoperitoneal shunting to alleviate the symptoms.

Disseminated cysticercosis is a very rare infectious disease. ${ }^{1}$ It is important to recognise disseminated cysticercosis clinically and to perform appropriate radiological investigations, because this condition requires an appropriate therapy. Patients who have not undergone treatment and who have active cysts remain at a risk of serious complications.

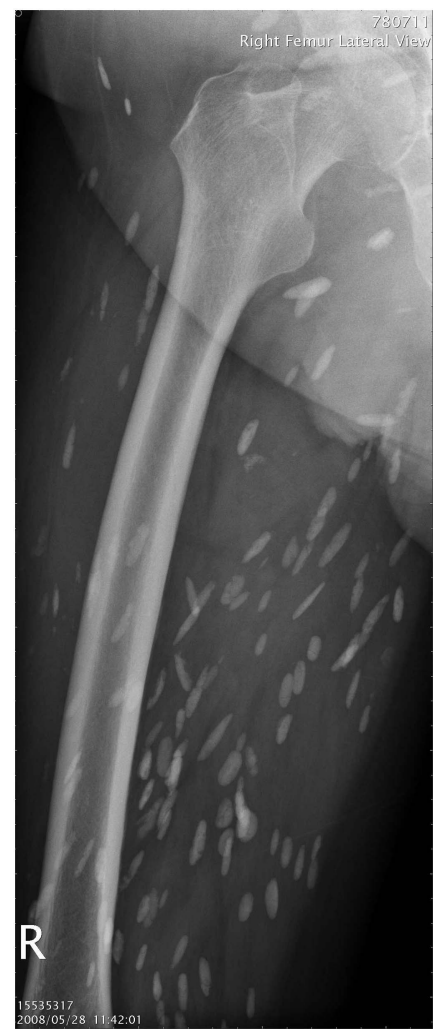

Figure 7 Femur film revealing numerous cysticerci on the right thigh.

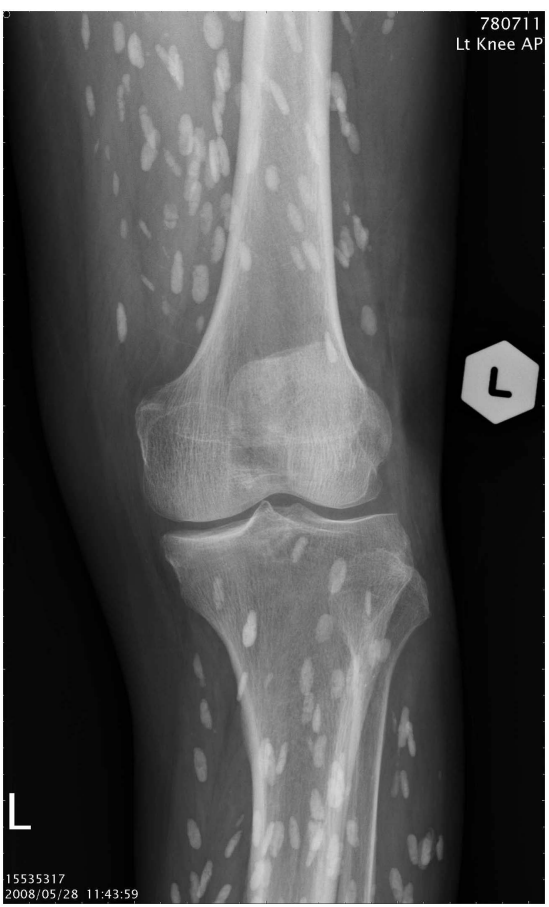

Figure 8 Knee film revealing numerous cysticerci on the left knee. 


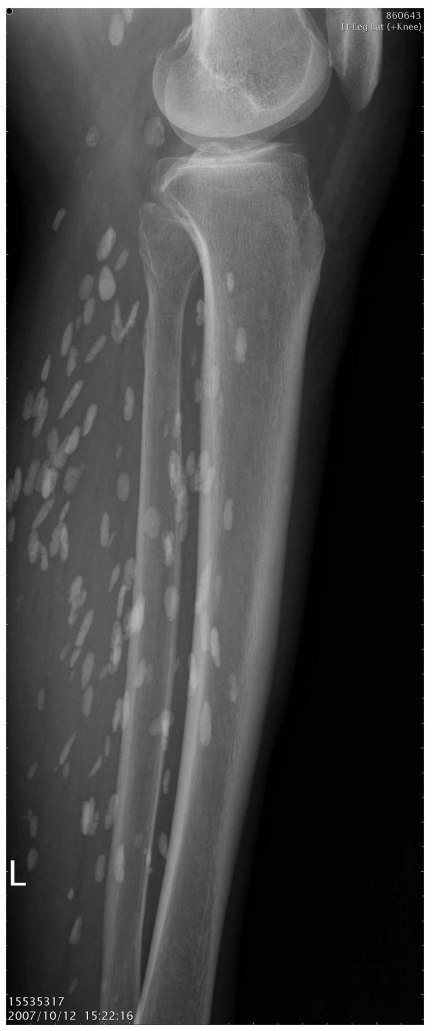

\section{Learning points}

- Disseminated cysticercosis is a rare form of cysticercosis in which the cysticerci spread throughout the body.

- It is important to recognise disseminated cysticercosis clinically and to perform appropriate radiological investigations, because this condition requires an appropriate therapy.

Contributors M-PL wrote the article, W-ST collated data and Y-LC revised the manuscript.

Competing interests None.

Patient consent Obtained.

Provenance and peer review Not commissioned; externally peer reviewed.

\section{REFERENCE}

1 Bhalla A, Sood A, Sachdev A, et al. Disseminated cysticercosis: a case report and review of the literature. J Med Case Rep 2008;2:137.

Figure 9 Leg film revealing numerous cysticerci on the left leg.

Copyright 2014 BMJ Publishing Group. All rights reserved. For permission to reuse any of this content visit

http://group.bmj.com/group/rights-licensing/permissions.

BMJ Case Report Fellows may re-use this article for personal use and teaching without any further permission.

Become a Fellow of BMJ Case Reports today and you can:

- Submit as many cases as you like

- Enjoy fast sympathetic peer review and rapid publication of accepted articles

- Access all the published articles

- Re-use any of the published material for personal use and teaching without further permission

For information on Institutional Fellowships contact consortiasales@bmjgroup.com

Visit casereports.bmj.com for more articles like this and to become a Fellow 